\title{
Socioeconomic Determinants of National Hospital Insurance Fund Health Contributions and Absorption: A Time Series Investigation Among the Counties in Kenya
}

\author{
Eugene Wanzetse Musungu \\ School of Medicine and Health Science, Kabarak University, Nakuru, Kenya
}

Email address:

drmusungu@gmail.com

\section{To cite this article:}

Eugene Wanzetse Musungu. Socioeconomic Determinants of National Hospital Insurance Fund Health Contributions and Absorption: A Time Series Investigation Among the Counties in Kenya. International Journal of Health Economics and Policy.

Vol. 6, No. 1, 2021, pp. 1-13. doi: 10.11648/j.hep.20210601.11

Received: January 25, 2021; Accepted: February 2, 2021; Published: February 20, 2021

\begin{abstract}
The aim of this investigation was to analyze socioeconomic determinants of National Hospital Insurance Fund Health contributions and absorption. The investigation was conducted in two study areas; the 47 counties and NHIF. First, the investigation targeted the 47 County Governments in Kenya. The study collected secondary data on the socioeconomic variables including; level of education, level of income and GDP from the respective 47 counties in Kenya collected from the Kenya Economic Review (2014-2020). The second investigation area was NHIF where collecting the annual audited financial statements from the NHIF between 2013/2014 - 2019/2020 financial years obtained from Kenya Auditor General, a total of 7 years resulting into 329 observations. The investigation employed a mixed research design, descriptive research design and casual-correlation research design. Findings on the relationship between educational level and income the socioeconomic determinants and NHIF contributions, the study established significant relationship between county education level $(\mathrm{r}=0.2813$, $\mathrm{p}=0.010)$, counties income $(\mathrm{r}=6.3706, \mathrm{p}=0.048)$ and NHIF contributions. Therefore the hypothesis $\mathrm{HO}_{1}$ that individual socioeconomic factors among the 47 counties in Kenya do not significantly influence NHIF contribution was rejected. On the other hand, findings on the relationship between socioeconomic determinants and NHIF absorptions, at individual socioeconomic determinants level significant relationship between education level, the study established significant relationship between county education level $(\mathrm{r}=0.02863, \mathrm{p}=0.007)$, counties income $(\mathrm{r}=6.3906, \mathrm{p}=0.040)$ and NHIF absorptions. Therefore the hypothesis $\mathrm{HO}_{2}$ that individual socioeconomic factors among the 47 counties in Kenya do not significantly influence NHIF absorption was rejected. Further findings on relationship between combined socioeconomic determinants and NHIF contributions established that all the determinants including counties GDP had significant relationship with NHIF contributions (Counties education level $r=0$. 02708, $\mathrm{p}=0.015$, counties income level $\mathrm{r}=0$. 0220, $\mathrm{p}=0.005$, counties GDP $\mathrm{r}=-1.17749, \mathrm{p}=0.015$ ). The hypothesis $\mathrm{HO}_{3}$ that the combined socioeconomic factors among the 47 counties in Kenya do not significantly influence NHIF contribution was rejected. Concerning the relationship between the combined socioeconomic determinants and NHIF absorption, the study also established that all the determinants including counties GDP had significant relationship with NHIF absorptions (Counties education level $\mathrm{r}=0.02766, \mathrm{p}=0.010$, counties income level $\mathrm{r}=0.0224$, $\mathrm{p}=0.003$, counties GDP $\mathrm{r}-1.207783, \mathrm{p}=0.010$ ). The hypothesis $\mathrm{HO}_{4}$ that the combined socioeconomic factors among the 47 counties in Kenya do not significantly influence NHIF absorption was rejected.
\end{abstract}

Keywords: Socioeconomic Determinants, Health Insurance Contributions, Health Insurance Assurance, Health Insurance Economics

\section{Introduction}

Low and medium-income countries (LMICs) are increasingly adopting universal health coverage (UHC) as their health policy priority [1]. In order to achieve UHC, countries need to increase the scope of services they provide their citizens, extend population coverage through a prepayment mechanism, and reduce the proportion of direct costs that citizens pay for 
accessing health care services. Kenya is committed to achieving the UHC commitment by 2022.

There are a variety of health funding initiatives in Kenya, funded by government (national and county) tax revenues and donor support, the National Hospital Insurance Fund (NHIF) through member donations, private health insurance companies through member contributions and out-of-pocket spending by individuals at points of service. Health care procurement is carried out by (1) supply-side grants to public facilities by national and county governments, such as county health departments providing county hospitals with line budgets to finance the delivery of services within the county to residents; (2) the procurement and payment by the NHIF of services rendered to its registered members by public and private health facilities in Kenya; and (3) the contracting and payment by private health insurance companies of services rendered to their registered members by private health facilities [2].

In Kenya, the National Hospital Insurance Fund (NHIF) system is also a more competitive health insurance scheme that offers cost insurance that is considerably lower than the fair actuarial price for most socio-economic classes in the world [3]. Since Kenya and individual counties, especially through the NHIF, are pushing for expanded insurance coverage, it is important to understand the entire scope of use in order to ensure its effectiveness in achieving its intended goals of Universal Health Care (UHC). In 1998, an Act of Parliament, which was later amended in 2012, established NHIF as a state corporation (Republic of Kenya, 2012). It raises funds mainly through member contributions, which are statutory deductions from persons employed in the formal sector (based on income levels) and voluntary (flat rate) for persons employed in the informal/self-employed sector. The NHIF committed itself in its strategic plan for 2014-2018 to increasing coverage in the informal sector and among indigent communities through government funding [4].

The government declared UHC as one of its 'Big Four' agenda, an elaborate roadmap for the country's development in the period 2018-2022. NHIF has been adopted as one of the vehicles to achieve UHCC with a target of 100 percent coverage by 2022 (Government of the Republic of Kenya, 2017), as well as a 50 percent drop in out-of-pocket spending by the same year [5]. However, despite the involvement of the NHIF in the nation for more than five decades and many policy recommendations, coverage appears to be weak.

Literature and government sources record varying coverage. Sessional Paper No. 7 on UHC reported 25 percent coverage. In the strategic analysis conducted to assess the efficacy of the NHIF in relation to its current mandate, several weaknesses were identified. The strategic analysis showed, among others, that the health insurance coverage of the NHIF in Kenya was low and that high attrition rates characterized informal sector involvement [6]. The study also highlighted that the NHIF was inefficient, with a benefit payout rate of 55 percent and a 45 percent share of operating costs in 2010.8. The report presented recommendations for changes in five key areas of the NHIF: (1) the political and regulatory framework, (2) governance, (3) financial sustainability, (4) performance and (5) quality. Interested readers can refer to the study for more details about its findings and recommendations. Since then, the NHIF has embarked upon several changes.

NHIF membership is mandatory for individuals in the formal sector and optional for individuals in the informal sector, the strategic review suggested that attempts to scale up NHIF coverage should focus on enrolling individuals in the informal sector [2]. International experience has shown that few nations have made substantial progress towards the UHC on a voluntary basis [7]. Like other LMICs, Kenya has a large proportion of informal sector workers. Furthermore, the proportion of enrolled individuals in the informal sector who subsequently did not renew their membership in 2017 was 73 percent, suggesting a high attrition rate [8]. Registration and protection of the informal sector using the voluntary participation method is problematic for several reasons. First, a substantial proportion of informal employees are less well-off in comparison to formal sector workers and thus have a lower capacity to pay for health insurance [9]. Secondly, because the informal sector is not organized into large groups, it is difficult to hire, control and collect regular contributions in a cost-effective administrative manner. Membership and premium payments are also largely voluntary, leading to poor acceptance and poor retention [10]. Third, the salaries of employees in the informal sector are always unpredictable [11], making it difficult to obtain premiums and rising attrition rates consistently.

Over the past eight years, the Kenyan government has initiated various changes, using the policy roadmap used to strengthen the NHIF's ability to deliver the UHC promise to Kenyans. In an empirical study, the researchers analyzed the socioeconomic determinants of the contributions and absorption of National Hospital Insurance Fund Health among the counties in Kenya. As far as the present socioeconomic drivers of NHIF and county contributions in Kenya are concerned, the study contributes to the health economics and policy body. The findings of this study refer not only to Kenya, but also to other contexts of the LMIC which have or are planning to implement a framework for health insurance contributions.

In 2015, the World Bank estimated NHIF coverage to be $18 \%$ [12], while the Kenya Integrated Household Budget Survey 2015/16 reports that national insurance coverage is 19\% (Kenya Integrated Household Budget Survey 2015/16) [13]. The Kenya Institute for Public Policy Research and Analysis reported in its March 2018 Policy Monitor that the Fund had about 6 million registered members, i.e. about 15 percent of Kenyans, benefiting approximately 36 percent of the population, given that there were an average of 3 dependents for each registered member. The information was gathered from the NHIF database. Embu's health insurance study focused largely on population subgroups, such as pregnant women [14], with an overall low coverage of $33.5 \%$ (Ministry of Health, 2015).

Although the de jure NHIF benefit package was 
comprehensive, it was argued that the spectrum of benefits enjoyed de facto by its members was limited because certain services were often not accessible from health care providers that NHIF had contracted to provide services to its members [15]. The expansion of the incentive package for both the CSS and the national system, along with equity implications, increases service reach. Given that membership between the informal sector and the disadvantaged is unlikely to increase significantly in the NHIF, only formal sector workers will benefit from the increase in the benefit package. Although the de jure NHIF benefit package was comprehensive, it was argued that the spectrum of benefits enjoyed de facto by its members was restricted because some services were often not available from health care providers contracted by NHIF to provide services to its members [15]. The extension, along with equity implications, of the incentive package for both the CSS and the national scheme increases the scope of operation. Given that membership between the informal sector and the disadvantaged is unlikely to increase significantly in the NHIF, only the formal sector workers will benefit from an increase in the benefit package. Health care facilities have also been shown to devote services to civil servants preferentially by founding, staffing, and equipping special clinics for civil servants in hospitals at the expense of the rest of the service areas serving non-civil servants and treating civil servants preferentially by enabling them, for example, to jump queues at the expense of non-civil servants [15].

The NHIF's fragmented risk pools also contribute to the inefficiency of the NHIF. The NHIF operates three schemes (CSS, the national scheme, and HISP), each of which provides different benefit packages [15]. Although all of these packages provide inpatient and outpatient care, there is a significant difference between them [15]. The different benefit packages and heterogeneity of risk pools weaken risk sharing and revenue cross-subsidization $(\mathrm{MoH})$ (2017), This results in higher risk-adjusted cost coverage than under a larger pool would have existed, thereby jeopardizing technical efficiency [11].

Socioeconomic factors were shown to determine the use of health insurance. Studies in many low-and middle-income countries such as Kenya, Zimbabwe, Nigeria and China, for example, have recorded age, level of education and job status as affecting the use of insurance [16-20]. The degree of education was also shown to be correlated with the use of health insurance by Nguyen et al in a cross-sectional study in Vietnam, where they conducted a household survey (2012). Household size and residence (urban vs. rural) were significantly associated with health insurance coverage according to research in Taiwan by [21]. Several studies have also shown in many low-and middle-income countries such as Sri Lanka, Taiwan, India, Kenya, Ghana and China that the higher the wealth index, the greater the likelihood of being in a health insurance system [16, 20-24].

Research on community members' use of the National Hospital Insurance Fund in Embu County, Kenya, found that the use of NHIF is low in Embu County. As in many low- and-middle-income contexts, even among those registered with the NHIF, out-of-pocket spending remains the dominant mode of payment for health services in this category. Sociodemographic characteristics decide the use of NHIF, particularly employment and wealth status [25]. The present research filled the study gap by analyzing the socioeconomic determinants of the usage of NHIF among the 47 Kenyan counties on the basis of panel data analysis and the findings presented in the results and discussions section. This study was based on sociodemographic determinants and used the primary method of data collection.

Determinants of the socio-demographic and health system were found to influence the use of NHIF. While efforts were made to increase NHIF coverage in the informal sector and in the poor and indigent sectors, enrollment was still more prevalent in the workforce and low in the lower income quintiles. Obstacles to the health system's use of the NHIF, in particular premium rates, incomplete information and difficulties obtaining the services needed, threaten to undo the gains made so far in health insurance and universal health coverage. These findings will help to define measures to enhance NHIF's utility and effectiveness [25]. With almost 500 accredited health facilities throughout Kenya, the NHIF is reputed to be Kenya's most widely available medical coverage to date, especially for inpatient benefactors [16]. workers' wages in the informal sector are frequently volatile making it difficult to consistently receive premiums and increasing attrition rates [17]. International experience has shown that few countries have made significant progress on a voluntary basis towards the UHC [18]. The experience in Kenya is that Health insurance centered mainly on population subgroups, such as pregnant women [19]. NHIF could only cover but limited services demanded by members [20].

From community health care, public providers are tiered: dispensaries, health centers, municipal hospitals, all run by county governments and finally national referral hospitals. According to the National Health Insurance Fund, 15 percent of Kenya's total population is covered by NHIF, which is about 88.4 percent of all individuals with health insurance in Kenya (2018). The number of principal members, including dependents, has risen from 4.7 million (2013/2014) to 7.6 million (2017/2018), which translates into approximately 30 million members. Membership in the NHIF is obligatory for all workers in the formal sector and is optional for the informal sector [4].

All Kenyans who have reached the age of 18 years have the NHIF available. The minimum salary from which donations are made has been raised to KES 5,999 and KES 150 contributions per month. For those earning more than or equivalent to KES 100000 , the top donation of KES 1,700 was set as of 1 April 2015 [4]. This has increased premium contributions fivefold. Contributions from KES 160 to KES 500 per household in the informal sector have been raised [4]. This increase in donations follows an enhanced reward program. The benefit package includes outpatient care and other services, such as health promotion and screening for diseases [26]. 
The NHIF's mandate is to provide all enrolled citizens, including their dependents, with social health insurance coverage in accordance with the 1998 NHIF Act. While the NHIF has covered those in the informal sector and the indigent community in recent years, the law requires those employed in the formal sector to register with the NHIF. Payments are made on the basis of a capitation, based on the number of persons enrolled in a particular facility. The NHIF website further indicates that the headings per beneficiary are between KES 1000 and KES 1400, respectively [27]. All forms of health facilities are certified by the Fund, including: national referral hospitals; county hospitals; health centers; clinics; specialist clinics; centers for imaging and laboratory diagnostics; pharmacies; and licensed drug dispensing outlets (ADDOs).

In Kakamega District, Kenya, in a study on strategies to improve the use of Informal Sector Communities' National Hospital Insurance Fund Scheme for Medical Cover. The results revealed that the NHIF's perceived negative attitude was due to inadequate marketing tactics, insufficient awareness of the insurance functions of the NHIF's medical scheme, as well as negative media advertisements about the NHIF's poor management. Furthermore, most participants perceived the design features of the scheme as an obstacle to participation. Both study participants saw the NHIF approach as beneficial. The insured were less satisfied with the care given them, according to the survey [28].

The NHIF scheme was seen by the participants as helpful in promoting access to health care for individuals in the informal sector. Both the protected and uninsured respondents seemed to recognize the efficacy of the NHIF method in accessing health care. Findings from the FGDs have shown that a number of individuals in the informal sector can use the NHIF system to access health services. However, rigid system design features and insufficient awareness of the NHIF's insurance position seem to hinder involvement in the scheme, the poor image of the structure and the poor outreach campaigns of the scheme. The low participation in the NHIF scheme, particularly when members of the NHIF scheme still have high out-of-pocket expenses, such as travel costs to accredited health facilities, buying medicines such as non-members of the scheme and inflexible scheme design features such as rigid deadlines for paying contributions, can be explained by unmet health care needs for NHIF members [28]. This finding confirms the findings of a similar study which revealed that the design features of the NHIF system were an obstacle to the registration of people living in the slums of Nairobi, Kenya [16].

\section{Problem Statement}

Analytical work on equity in developing/less developed nations (LDCs) has become more common since the beginning of the 2000s. An review of the literature provides a number of findings on the equity of the multiple sources of health care financing. First, while out-of-pocket payment (OOPP) is commonly accepted as a regressive source of funding for health care in DCs, findings in LDCs are not as reliable [29]. The investigator set out to investigate the social determinants of health contributions and use of the National Hospital Insurance Fund in Kenya due to conflicting health care financing results. The fund had 7.6 million (2017/2018), according to the NHIF, of which about 99 percent was covered by formal sector workers. This means that about 30 million beneficiaries are covered, with an average family size of four individuals. From 2013/2014 to 2017/2018, membership grew dramatically from 4,7 to 7,65 million members. In the same period, the contribution of the National Scheme members increased from 29.8 billion to 32.9 billion, and outpatient services expenditure increased by $48 \%$ (5.07 billion to 7.5 billion Kenyan shillings) [30]. These figures include representatives of the 47 counties in Kenya who are contributing to the NHIF and who are also benefiting from the formal employment or informal sector NHIF (absorption). These members are affected by various socioeconomic factors in their decision to contribute to the NHIF and also have an understanding of how their contributions should be used (absorption). The degree to which these socio-economic determinants influence both their contributions to the fund and their understanding of the use (absorption) of NHIF is an interest in research in health economics that has been addressed in the current study and the results discussed in section 3 of this paper.

The investigation tested the following hypotheses; $\mathrm{HO}_{1}$ : Individual socioeconomic factors among the 47 counties in Kenya do not significantly influence NHIF contributions. $\mathrm{HO}_{2}$ : Individual socioeconomic factors among the 47 counties in Kenya do not significantly influence NHIF absorption. $\mathrm{HO}_{3}$ : The combined socioeconomic factors among the 47 counties in Kenya do not significantly influence NHIF contributions. $\mathrm{HO}_{4}$ : The combined socioeconomic factors among the 47 counties in Kenya factors do not significantly influence NHIF absorption. The section first presents the Hausman test which indicated the choice of model to adopt for the regression analysis between the socioeconomic determinants and NHIF contributions and absorptions and lastly the regression results.

\section{Materials and Methods}

\subsection{Study Area and Target Population}

Two areas of the study were the focus of the investigation; the 47 counties and the NHIF. First, in the inquiry, the 47 county governments in Kenya were attacked. The study gathered secondary data from the Kenya Economic Review on socioeconomic variables, including education level, income level and GDP, from the respective 47 counties in Kenya (2014-2020). The second investigation area was NHIF where the investigator collected the annual audited financial statements between 2013/2014 - 2019/2020 financial years obtained from Kenya Auditor General, a total of 7 years resulting into 329 observations. 


\subsection{Research Design and Sample Size}

In order to obtain an in-depth understanding of the relationship between socioeconomic determinants and NHIF contributions and absorption, the investigation employed a mixed research design, descriptive research design and casual-correlation research design. In the descriptive design, the researcher is permitted to test the different aspects in their natural state without modifying them in any way. This design also helps the student to work out descriptive statistics that describe the relationship between variables. To evaluate the effect of socioeconomic determinants on NHIF contributions and absorption, the researcher successfully used this approach to analyze.

Since this investigation sought to explain a casual association between socioeconomic determinants and NHIF contributions and absorption in Kenya, a correlation study design was used. From panel data giving annual figures of the dependent and independent variables in the model during the investigation's development, a regression model was designed. The information was used to develop and demonstrate the model's reliability, thereby helping to understand the link between socioeconomic determinants and NHIF contributions and absorption.

\subsection{Ethical and Consenting Consideration}

Ethical analysis and approval of panel data were followed in the inquiry. The study extracted the data published by the Office of the Auditor General of Kenya on the financial status of the NHIF for 2014-2020 to meet the quality of ethical consideration. The audited financial statements that have been released have already been validated by the National Assembly of Kenya and are therefore accurate for the intended investigation. Secondly, the analysis extracted the socio-economic variables (education level, income level and GDP) reported in the Kenya Economic Review 20142020 in the 47 counties in Kenya.

\subsection{Data Analysis and Model Specifications}

The study used panel data for 7 years, beginning from 2014 to 2020, to conduct the research analysis. As opposed to cross-sectional dataAs they contain accurate data, panels are very critical and increase precision (Blundell \& Bond, 1998) and (Hoechle, 2007). According to Cheng Hsiao (2004), panel data usually gives the researcher a large number of data points, thereby increasing freedom on the one hand and reducing collinearity on the other hand, which means that econometric calculation effectiveness can be achieved or increased. Gujarati (2012) has proposed different estimation methods that can be used to estimate the panel data pooled by Ordinary Least Square (OLS), Random Effect (RE) and Fixed Effect (Fixed Effect) (FE).

Finally, the importance of the effect of the independent variables on the dependent variable was checked using the panel data model. As shown below, the dependent variable in the model of panel data analysis is;

$$
\mathrm{Y}_{i t(1,2)}=\beta 0+\beta 1 \mathrm{X} 1_{i t}+\beta 2 \mathrm{X} 2_{i t}+\beta 3 \mathrm{X} 3_{i t}+\mathrm{u} i t
$$

Where:

$\beta 0(i=1 \ldots \mathrm{n})$ is the intercept.

$\mathrm{Y}_{i t(1,2)}=$ dependent variable $(\mathrm{DV})$, that is $(1=$ Contribution, 2=Absorption)

$\mathrm{X} i t=$ independent variables (IV), that is related

$\mathrm{X} 1=$ Education level

$\mathrm{X} 2=$ Income level

$\mathrm{X} 3=\mathrm{GDP}$

$\beta_{(1 \ldots 3)}=$ coefficient for that IV, uit=between entity error term $i=$ entity and

$t=$ time

\section{Findings and Discussions}

\subsection{Descriptive Statistics}

Table 1 presents the descriptive statistics results of the socioeconomic indicators of the 47 County Governments. The indicators included the number of people who had attained at least basic education, whereas basic education was measured by those who had attained at least secondary school education measured in terms of 100,000 . The mean education level for the 7 years was 523,900 with standard deviation of 562,300 . The minimum people with secondary education were 317,861 and maximum was 620,460 . The descriptive statistics was a social determinant hypothesized not influencing the contribution and utilization of NHIF.

Table 1. Descriptive Statistics of Socioeconomic Determinants and Health Insurance Coverage.

\begin{tabular}{|c|c|c|c|c|c|}
\hline Variable & Obs & Mean & Std. Dev. & Min & Max \\
\hline education & 329 & 523,900 & 562,300 & 317,861 & 620,460 \\
\hline income & 329 & 135,653 & 192,167 & 12,741 & $1,507,018$ \\
\hline GDP (\%) & 329 & 2.0 & 3.1 & 0.1 & 21.7 \\
\hline NHIF absorption Rate & 329 & 18.9 & 10.8 & 4.9 & 32.7 \\
\hline NHIF contribution & 329 & 26.1 & 11.2 & 8.7 & 39.1 \\
\hline
\end{tabular}

Obs=Number of Observations, Std. Dev.=Standard Deviation, Min=Minimum, Max=Maximum.

The results on income established a mean Kshs. 135,653 with a standard deviation of Kshs. 192,167 with a minimum income of Kshs. 12,741 with a maximum Kshs. 1,507,018. The mean GDP was 2.0 with standard deviation of 3.1 , a minimum of 4.9 and maximum of 32.7. The NHIF absorption rate mean was Kshs. 18.9 Billion with standard deviation of Kshs. 10.8, a minimum Kshs 4.9 Billion and maximum Kshs. 32.7 Billions. The contribution towards NHIF rate mean was Kshs. 26.1 Billion with standard deviation of Kshs. 11.2, a minimum Kshs 8.7 Billion and maximum Kshs. 39.1 
Billions.

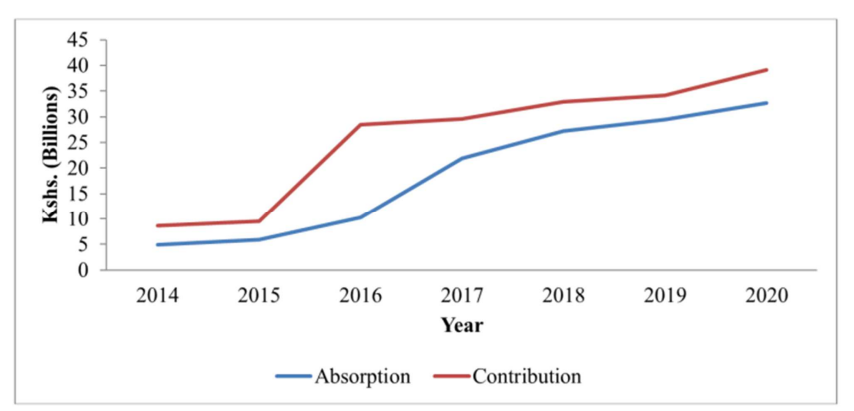

Figure 1. Descriptive Statistics Comparison between NHIF Contribution and Absorption.

The investigation also analyzed the difference between NHIF Contribution and absorption which was important in understanding whether the contributed premium was directed towards its intentions. The investigation established that between 2014-2015 the NHIF contribution and absorption was so close indicating that much of the premium contribution was absorbed in paying for the medical bills incurred by the contributors. Between 20152020 , the contribution and absorption was grew wider indicating that much of the premium contribution was used in other bills not related to the medical bills incurred by the contributors.

\subsection{Influence of Socioeconomic Determinants on NHIF Contribution and Absorption}

This section presents the panel data analysis results of influence of socioeconomic determinants on NHIF contribution and absorption. This section also tested the following $\mathrm{HO}_{1}$ : Individual socioeconomic factors among the 47 counties in Kenya do not significantly influence NHIF contributions. $\mathrm{HO}_{2}$ : The combined socioeconomic factors among the 47 counties in Kenya do not significantly influence NHIF absorption. $\mathrm{HO}_{3}$ : Individual socioeconomic factors among the 47 counties in Kenya do not significantly influence NHIF contributions. $\mathrm{HO}_{4}$ : The combined socioeconomic factors among the 47 counties in Kenya factors do not significantly influence NHIF absorption. The section first presents the Hausman test which indicated the choice of model to adopt for the regression analysis between the socioeconomic determinants and NHIF contributions and absorptions and lastly the regression results.

\subsection{Hausman Test}

The relationship between socioeconomic factors and NHIF coverage was evaluated in the panel data regression model, the fixed effect model and random effect model were fitted, and the Hausman test was used to decide the best multivariate model to adopt the two. Table 2 displays the Hausman specification test results for the multivariate model of determinants of financial distress.

The null hypothesis of Hausman Test is that Random Effects model is preferable and since the results in Table 2 indicate $\mathrm{P}$-value $=0.0870$ which is greater than 0.05 confidence level, the null hypothesis is not rejected and hence Random effects model was employed for the analysis of influence of the socioeconomic determinants on NHIF contribution and absorption as per Table 2 . This implies that the most appropriate model to explain the relationship between the socioeconomic determinants and NHIF contribution and absorption was the random effects regression model.

Table 2. Hausman Test.

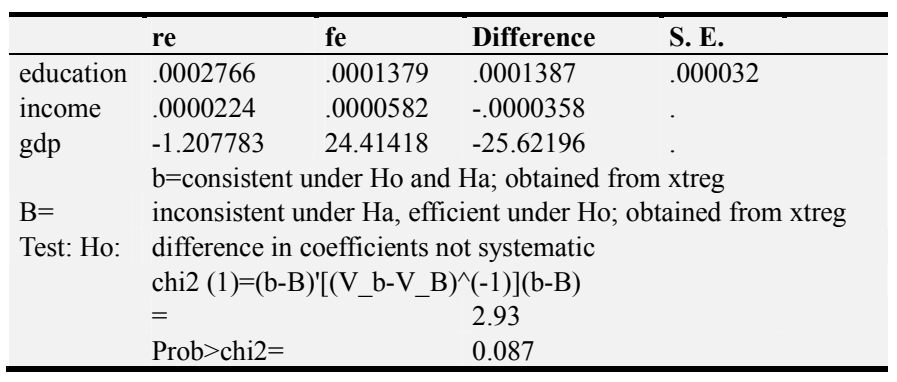

\subsection{Regression Results of Education Level of the County Governments and NHIF Contributions}

To evaluate the forces and relationships, statistical models were mounted. The equipped models considered that the collected information was panel data consisting of components of both cross-sectional and time series. The data included a cross-section of 47 individuals over a period of just 7 years. For all seven years, each of the data institutions had information required, suggesting that the panels were strongly balanced. The general form of the model structure of the random effect adopted was the form given by the following equation;

$$
\mathrm{Y}_{\mathrm{it}}=\mathrm{a}_{0}+\sum_{\mathrm{i}=1}^{2} \beta 1 \mathrm{X} 1 \mathrm{it}+\mu \mathrm{it} \ldots \text {. random effect equation }
$$

In the random effect model, where Xit is the predictor variable that is the education level as social determinants and Yit is the dependent variable, the NHIF contribution assumes that the likelihood of NHIF contribution varies over time but has a random effect across entities in the random effect model, $\beta 1$ is the coefficients of the regressor variables and $\mathrm{a} 0$ is the coefficient.

Table 3. Random Effect of Education Level and NHIF Contribution.

\begin{tabular}{|c|c|c|c|c|c|c|}
\hline SS & df & MS & & $\begin{array}{l}\text { Number } \\
\text { of obs }\end{array}$ & 329 & \\
\hline & & & & & $\mathrm{F}(1,327)$ & 6.64 \\
\hline Model & 820.6 & 1 & 820.6 & & Prob $>$ F & 0.0104 \\
\hline \multirow[t]{2}{*}{ Residual } & 40406.6 & 327 & 123.6 & & R-squared & 0.2199 \\
\hline & & & & & $\begin{array}{l}\text { Adj R- } \\
\text { squared }\end{array}$ & 0.2169 \\
\hline \multirow{4}{*}{$\begin{array}{l}\text { Total } \\
\text { contrib } \\
\text { education } \\
\text { cons }\end{array}$} & 41227.2 & 328 & 125.7 & & Root MSE & 11.12 \\
\hline & Coef. & Std. Err. & $\mathrm{t}$ & $\mathrm{P}>\mathrm{t}$ & [95\% Conf. & Interval] \\
\hline & 0.2813 & .0001092 & 2.58 & 0.010 & 0.0000666 & 0.0004961 \\
\hline & 24.59761 & .8382617 & 29.34 & 0.000 & 22.94855 & 26.24668 \\
\hline
\end{tabular}

The overall $\mathrm{R}^{2}$ was 0.2199 indicating that $22 \%$ of the variance of NHIF contribution is explained by education level in the 47 County Governments compared to $77 \%$ which 
were explained by other factors outside the current study. The study established a statistically significant relationship between education level in the 47 County Governments and NHIF contribution $(\mathrm{r}=0.2813, \mathrm{p}=.001)$ as per table 3 .

The $\mathrm{F}$ value for NHIF contribution was significant (F1, $327)=6.64, p=0.0104$ ). This implies that there is a significant effect of education level in the 47 County Governments on NHIF contribution in Kenya. Education level in the 47 County Governments therefore could be used to predict the NHIF contribution in Kenya. This finding indicated that an increase in the education level in the 47 County Governments by 1 unit will lead to increase in NHIF contribution by 0.2813 multiple units. The null hypothesis that $\mathrm{HO}_{1}$ that individual socioeconomic factors among the 47 counties in Kenya do not significantly influence NHIF utilization was rejected. This implies that education level in the 47 County Governments was a predictor of the NHIF contribution in Kenya.

\subsection{Regression Results of Income by the County Governments and NHIF Contributions}

For all seven years, each of the data institutions had information required, suggesting that the panels were strongly balanced. The general form of the model structure of the random effect adopted was the form given by the following equation;

$$
\mathrm{Y}_{\mathrm{it}}=\mathrm{a}_{0}+\sum_{\mathrm{i}=1}^{42} \beta 1 \mathrm{X} 2 \mathrm{it}+\mu \mathrm{it} \ldots . . \text {.random effect equation }
$$

Where Xit is the predictor variable that is the revenue as economic determinants and Yit is the dependent variable, the NHIF contribution assumes the homogeneity of estimates across entities in the random effect model and that the independent variable that the probability of NHIF contribution varies over time but has a random effect across entities, $\beta 1$ is the coefficients of the regressor variables and a0 was the error term.

Table 4. Random Effect of Income and NHIF Contribution.

\begin{tabular}{|c|c|c|c|c|c|c|}
\hline df & MS & & & Number of obs 329 & $\mathrm{~F}(1,382)$ & 17.34 \\
\hline Model & 491.446862 & 1 & 491.446862 & & Prob $>$ F & 0.0478 \\
\hline \multirow[t]{2}{*}{ Residual } & 40735.7447 & 327 & 124.574143 & & R-squared & 0.3119 \\
\hline & & & & & Adj R-squared & 0.3089 \\
\hline Total & 41227.1916 & 328 & 125.692657 & & Root MSE & 11.161 \\
\hline contribCoef. & & Std. Err. & $\mathrm{t}$ & $\mathrm{P}>\mathrm{t}$ & [95\% Conf. & Interval] \\
\hline income & 6.3706 & 3.2106 & 1.99 & 0.048 & 6.0808 & 0.0000127 \\
\hline
\end{tabular}

The overall $\mathrm{R}^{2}$ was 0.3119 indicating that $31 \%$ of the variance of NHIF contribution is explained by income level in the 47 County Governments compared to $69 \%$ which were explained by other factors outside the current study. The study established a statistically significant relationship between income level in the 47 County Governments and NHIF contribution $(r=6.3706, p=.014)$ as per table 4 . The $F$ value for NHIF contribution was significant $(F 1,382)=17.34$, $\mathrm{p}=0.048$ ). This implies that there is a significant effect of income level in the 47 County Governments on NHIF contribution in Kenya. Income level in the 47 County Governments therefore could be used to predict the NHIF contribution in Kenya. This finding indicated that an increase in the income level in the 47 County Governments by 1 unit will lead to increase in NHIF contribution by 6.3706 multiple units. This implies that income level in the 47 County Governments was a predictor of the NHIF contribution in Kenya. This outcome is comparable to the fact that households have a positive effect as household income rises on the purchase of health insurance as a regular good [34]. Age, level of education and employment status as influencing insurance uptake by patients [35]. These some of the statistical confirmation that health insurance intake is increasing among LMICs [36]. Households therefore have a positive impact on the purchase of health insurance as a standard good as household income increases [37, 38]. The restriction would also cause the insurance policy demand to have a positive income elasticity, while without it, the health capital expenditure demand would have a positive income elasticity.

\subsection{Regression Results of GDP of the County Governments and NHIF Contributions}

For all seven years, each of the data institutions had information required, suggesting that the panels were strongly balanced. The general form of the model structure of the random effect adopted was the form given by the following equation;

$$
\mathrm{Y}_{\mathrm{it}}=\mathrm{a}_{0}+\sum_{\mathrm{i}=1}^{2} \beta 1 \mathrm{X} 3 \mathrm{it}+\mu \mathrm{it} \ldots \ldots . . . \text { random effect equation }
$$

Where $\mathrm{Xit}$ is the predictor variable that is the GDP as economic determinants and Yit is the dependent variable, the NHIF contribution assumes homogeneity of estimates across entities in the random effect model and that the independent variable that the likelihood of NHIF contribution varies over time but has a random effect across entities, $\beta 1$ is the regressor variables' coefficients and $\mathrm{a} 0$ is the error term.

The overall $\mathrm{R}^{2}$ was 0.2025 indicating that $20 \%$ of the variance of NHIF contribution is explained by GDP in the 47 County Governments compared to $69 \%$ which were explained by other factors outside the current study. The study established a statistically significant relationship between GDP in the 47 County Governments and NHIF contribution $(\mathrm{r}=0.1812, \mathrm{p}=.3659)$ as per table 5 . 
Table 5. Random Effect of GDP and NHIF Contribution.

\begin{tabular}{|c|c|c|c|c|c|c|c|}
\hline & & & & & Number of obs & & 329 \\
\hline df & MS & & & & & & \\
\hline Model & 103.09 & 1 & 103.09 & & $\mathrm{~F}(1,327)$ & 0.82 & \\
\hline \multirow[t]{3}{*}{ Residual } & 41124.09 & 327 & 125.8 & & Prob $>F$ & 0.3659 & \\
\hline & & & & & R-squared & 0.2025 & \\
\hline & & & & & Adj R-squared & 0.0605 & \\
\hline Total & 41227.1916 & 328 & 125.692657 & & Root MSE & 11.214 & \\
\hline contribCoef. & & Std. Err. & $\mathrm{t}$ & $\mathrm{P}>\mathrm{t}$ & [95\% Conf. & Interval] & \\
\hline gdp & .1811768 & .2001062 & 0.91 & 0.366 & -0.212481 & 0.5748347 & \\
\hline cons & 25.70904 & .7365175 & 34.91 & 0.00 & 24.26013 & 27.15795 & \\
\hline
\end{tabular}

The $\mathrm{F}$ value for NHIF contribution was significant (F1, $382)=17.34, p=0.3659$ ). This implies that there is no significant effect of GDP in the 47 County Governments on NHIF contribution in Kenya. GDP level in the 47 County Governments therefore could not be used to predict the NHIF contribution in Kenya. The null hypothesis that $\mathrm{HO}_{1}$ that individual socioeconomic factors among the 47 Counties in Kenya do not significantly influence NHIF contribution was rejected. This is because the study established significant relationship between level of education and level of income had significant relationship with NHIF contribution in Kenya. GDP alone did not have any relationship with NHIF contribution in Kenya.

\subsection{Regression Results of Education Level of the County Governments and NHIF Absorption}

In the relationship between the educational level of the 47
County Government and NHIF absorption, each of the data entities had information needed for all seven years, indicating that the panels were strongly balanced. The general form of the model structure of the random effect adopted was the form given by the following equation;

$$
\mathrm{Y}_{\mathrm{it}}=\mathrm{a}_{0}+\sum_{\mathrm{i}=1}^{2} \beta 1 \mathrm{X} 1 \mathrm{it}+\mu \mathrm{it} . \ldots . . \text {.random effect equation }
$$

Where Xit is the predictor variable that is the degree of education as social determinants and Yit is the dependent variable, NHIF contribution assumes homogeneity of estimates across entities in the random effect model and that the independent variable assumes that the likelihood of NHIF contribution varies over time but has a random effect across entities, $\beta_{1}$ is the coefficients of the regressor variables and $\mathrm{a}_{0}$ is the coefficient of the predictor variable and $\mu \mathrm{it}$ is error term.

Table 6. Random Effect of Education Level and NHIF Absorption.

\begin{tabular}{|c|c|c|c|c|c|c|}
\hline & & & & & Number of obs & 329 \\
\hline Source & SS & $\mathrm{df}$ & MS & & $\mathrm{F}(1,327)$ & 7.38 \\
\hline Model & 850.2 & 1 & 850.2 & & Prob $>F$ & 0.0069 \\
\hline Residual & 37655.5 & 327 & 115.2 & & R-squared & 0.2221 \\
\hline Total & 38505.6 & 328 & 117.4 & & $\begin{array}{l}\text { Adj R-squared } \\
\text { Root MSE }\end{array}$ & $\begin{array}{l}0.0191 \\
10.731\end{array}$ \\
\hline absob & Coef. & Std. Err. & $\mathrm{t}$ & $\mathrm{P}>\mathrm{t}$ & [95\% Conf. & Interval] \\
\hline education & 0.02863 & .0001054 & 2.72 & 0.007 & 0.000079 & 0.0004937 \\
\hline
\end{tabular}

The overall $\mathrm{R}^{2}$ was 0.2221 indicating that $22 \%$ of the variance of NHIF absorption is explained by education level in the 47 County Governments compared to $78 \%$ which were explained by other factors outside the current study. The study established a statistically significant relationship between education level in the 47 County Governments and NHIF absorption $(\mathrm{r}=0.02863, \mathrm{p}=.007)$ as per table 6 .

The $F$ value for NHIF absorption was significant ( $F 1$, $327)=7.38, \mathrm{p}=0.007$ ). This implies that there is a significant effect of education level in the 47 County Governments on NHIF absorption in Kenya. Education level in the 47 County Governments therefore could be used to predict the NHIF contribution in Kenya. This finding indicated that an increase in the education level in the 47 County Governments by 1 unit will lead to increase in NHIF absorption by 0.2813 multiple units. This implies that education level in the 47 County Governments was a predictor of the NHIF absorption in Kenya. These results were corroborated by the fact that roughly two-thirds had tertiary education, while 12.5 percent either had primary or no education [31]. Half of the respondents were ranked as highly qualified employees $(53.3 \%)$; nearly a third $(31.1 \%)$ as low-qualified employees; and just $3.1 \%$ were senior managers. The median monthly total expenditure for households was US\$ 533.3.5. Only $2.6 \%$ said their health was bad or very poor. However, almost a third took chronic medicine.

\subsection{Regression Results of Income by the County Governments and NHIF Absorption}

For all the 7 years of the relationship between revenue levels in the 47 county governments and NHIF absorption, each of the data entities had information needed and indicated that the panels were strongly balanced. The general form of the model structure of the random effect adopted was the form given by the following equation;

$$
\mathrm{Y}_{\mathrm{it}}=\mathrm{a}_{0}+\sum_{\mathrm{i}=1}^{42} \beta 1 \mathrm{X} 2 \mathrm{it}+\mu \mathrm{it} . . \text { random effect equation }
$$


Where Xit is the predictor variable that is the revenue as economic determinants and Yit is the dependent variable, NHIF contribution assumes homogeneity of estimates across entities in the random effect model and that the independent variable assumes that the likelihood of NHIF absorption varies over time but has a random effect across entities, $\beta_{1}$ is the coefficients of the regressor variables and $a_{0}$ is the coefficient of the predictor variable and $\mu$ it is error term.

Table 7. Random Effect of Income and NHIF Absorption.

\begin{tabular}{|c|c|c|c|c|c|c|}
\hline & & & & & Number of obs & 329 \\
\hline Source & SS & Df & MS & & $\mathrm{F}(1,327)$ & 4.26 \\
\hline Model & 495.214442 & 1 & 495.2 & & Prob $>$ F & 0.0398 \\
\hline Residual & 38010.4094 & 327 & 116.2 & & R-squared & 0.329 \\
\hline & & & & & Root MSE & 10.781 \\
\hline absob & Coef. & Std. Err. & $\mathrm{t}$ & $\mathrm{P}>\mathrm{t}$ & {$[95 \%$ Conf. } & Interval] \\
\hline income & 6.3906 & 3.1006 & 2.06 & 0.04 & $3.00 \mathrm{E}-07$ & 0.0000125 \\
\hline
\end{tabular}

The overall $\mathrm{R}^{2}$ was 0.329 indicating that $33 \%$ of the variance of NHIF absorption is explained by income level in the 47 County Governments compared to $67 \%$ which were explained by other determinants outside the current study. The study established a statistically significant relationship between income level in the 47 County Governments and NHIF absorption $(r=6.3906, p=.004)$ as per table 7 .

The $F$ value for NHIF absorption was significant (F1, $327)=4.26, p=0.0398$ ). This implies that there is a significant effect of income level in the 47 County Governments on NHIF absorption in Kenya. Income level in the 47 County Governments therefore could be used to predict the NHIF absorption in Kenya. This finding indicated that an increase in the income level in the 47 County Governments by 1 unit will lead to increase in NHIF absorption by 6.3906 multiple units. This implies that income level in the 47 County Governments was a predictor of the NHIF absorption in Kenya.

\subsection{Regression Results of GDP of the County Governments and NHIF Absorption}

Each of the data entities had details on the relationship between GDP and NHIF absorption needed for all 7 years, indicating that the panels were strongly balanced. Of the form given by the following equation, the general form of the random effect model structure adopted was;

$\mathrm{Y}_{\mathrm{it}}=\mathrm{a}_{0}+\sum_{\mathrm{i}=1}^{2} \beta 1 \mathrm{X} 3 \mathrm{it}+\mu \mathrm{it} \ldots \ldots \ldots$ random effect equation

Where $\mathrm{Xit}$ is the predictor variable that is the economic determinant of GDP and Yit is the dependent variable, NHIF absorption assumes the homogeneity of estimates across entities in the random effect model and the independent variable assumes that the likelihood of NHIF absorption varies over time but has a random effect across entities, $\beta_{1}$ is the coefficients of the regressor variables and $a_{0}$ is the coefficient of the predictor variable and $\mu$ it is error term.

Table 8. Random Effect of GDP and NHIF Absorption.

\begin{tabular}{|c|c|c|c|c|c|c|}
\hline & & & & & Number of obs & 329 \\
\hline Source & SS & df & MS & & $\mathrm{F}(1,327)$ & 0.85 \\
\hline Model & 99.3 & 1 & 99.3 & & Prob $>$ F & 0.3584 \\
\hline Residual & 38406.3 & 327 & 117.5 & & R-squared & 0.026 \\
\hline \multirow[t]{2}{*}{ Total } & 38505.6 & 328 & 117.4 & & Adj R-squared & -0.0005 \\
\hline & & & & & Root MSE & 10.837 \\
\hline absob & Coef. & Std. Err. & $\mathrm{t}$ & $\mathrm{P}>\mathrm{t}$ & [95\% Conf. & Interval] \\
\hline gdp & 0.1778521 & .1933808 & 0.92 & 0.358 & -0.2025754 & 0.5582795 \\
\hline
\end{tabular}

The overall $\mathrm{R}^{2}$ was 0.1779 indicating that $2.6 \%$ of the variance of NHIF absorption is explained by GDP in the 47 County Governments compared to $97.4 \%$ which were explained by other factors outside the current study. The study established a statistically significant relationship between GDP in the 47 County Governments and NHIF absorption $(\mathrm{r}=0.17792, \mathrm{p}=.3584)$ as per table 8 . The $\mathrm{F}$ value for NHIF absorption was significant $(F 1,327)=0.85$, $\mathrm{p}=0.3584$ ). This implies that there is no significant effect of GDP in the 47 County Governments on NHIF absorption in Kenya. GDP level in the 47 County Governments therefore could not be used to predict the NHIF absorption in Kenya. The second hypothesis $\mathrm{HO}_{2}$ that individual socioeconomic factors among the 47 counties in Kenya do not significantly influence NHIF absorption was rejected. The investigation therefore concludes that there was significant relationship between level of education and level of income had significant relationship with NHIF contribution in Kenya. Only GDP did not have any relationship with NHIF absorption in Kenya.

\subsection{Multivariate Regression Results of the Socioeconomic Factors and NHIF Contribution}

Each of the data entities had the requisite details on the combined relationship between the socioeconomic determinants and the NHIF contribution for all seven years, indicating that the panels were well balanced. The general 
form of the structure of the random effect model adopted was the form given by the following equation;

$$
\mathrm{Y}_{i t}=\beta 0+\beta 1 \mathrm{X} 1_{i t}+\beta 2 \mathrm{X} 2_{i t}+\beta 3 \mathrm{X} 3_{i t}+\mathrm{uit} \ldots \ldots \text {. random effect }
$$

Where Xit is the determinant predictor variable and Yit is the dependent variable, the NHIF contribution assumes homogeneity of estimates across entities in the random effect model and the independent variable assumes that the likelihood of NHIF contribution varies over time but has a random effect across entities, $\beta_{1}$ is the coefficients of the regressor variables and $a_{0}$ is the coefficient of the predictor variable and $\mu$ it is error term.

\begin{tabular}{|c|c|c|c|c|c|c|}
\hline \multirow[t]{2}{*}{ SS } & & df & \multicolumn{2}{|l|}{ MS } & \multirow{2}{*}{$\begin{array}{l}\text { Number of obs } \\
\mathrm{F}(3,325)\end{array}$} & \multirow{2}{*}{$\begin{array}{l}329 \\
4.99\end{array}$} \\
\hline & & & & & & \\
\hline Model & 1815.7 & 3 & 605.2 & & Prob $>$ F & 0.0021 \\
\hline Residual & 39411.5 & 325 & 121.3 & & R-squared & 0.344 \\
\hline Total & 41227.2 & 328 & 125.7 & & Adj R-squared & 0.0352 \\
\hline & & & & & Root MSE & 11.012 \\
\hline contrib & Coef. & Std. Err. & $\mathrm{t}$ & $\mathrm{P}>\mathrm{t}$ & [95\% Conf. & Interval] \\
\hline education & 0.02708 & .0001111 & 2.44 & 0.015 & 0.0000522 & 0.0004895 \\
\hline income & 0.0220 & 7.7206 & 2.85 & 0.005 & 6.7806 & 0.0000372 \\
\hline gdp & -1.17749 & .4816577 & -2.44 & 0.015 & -2.12505 & -0.2299295 \\
\hline cons & 24.02636 & .8893599 & 27.02 & 0.000 & 22.27673 & 25.77599 \\
\hline
\end{tabular}

Table 9. Multivariate Random Effect of Socioeconomic Factors and NHIF Contribution.

The overall $\mathrm{R}^{2}$ was 0.344 indicating that $34 \%$ of the variance of NHIF contribution is explained by the socioeconomic determinants in the 47 County Governments compared to $69 \%$ which were explained by other factors outside the current study. In the 47 County Governments and NHIF contribution, the analysis identified a statistically significant relationship between the socioeconomic determinants as per Table 9. The $F$ value for NHIF contribution was significant $(F 1,325)=4.99, p=0.0021)$. This implies that there is a significant effect of education level in the 47 County Governments on NHIF contribution in Kenya. Education level in the 47 County Governments therefore could be used to predict the NHIF contribution in Kenya.

This finding indicated that an increase in the education level in the 47 County Governments by 1 unit will lead to increase in NHIF contribution by 0.02708 multiple units. This implies that education level in the 47 County Governments was a predictor of the NHIF contribution in Kenya. The results also show that older people (60 years and older), whites, those in higher income groups and tertiary education who have possibly been with their current system for a long time will have 'market loyalty' and customer inertia, even though due to the subsidy, the new system provides better value for money. Furthermore, this research will more clearly define reasons and preferences for this [31]. Secondly, the level of income in the 47 county governments could therefore be used to predict the contribution of the NHIF in Kenya. This finding indicated that an increase in the income level in the 47 County Governments by 1 unit will lead to increase in NHIF contribution by 0.022 multiple units. This implies that income level in the 47 County Governments was a predictor of the NHIF contribution in Kenya. It was found that lower-income workers contribute a higher percentage of their wages to health benefits than higher-income employees, suggesting inequity in the insurance system of the government. Improving the quality of care in public facilities is important for improving public attitudes and promoting insurance adoption, especially among low-income households (Veloshnee, Matthew, Chersich, Olufunke, John, Ataguba, Nonhlanhla et al., 2013). Although at bivariate analysis the study established insignificant relationship between GDP and NHIF contribution, when the researcher carried out multivariate analysis, the study established a significant relationship between GDP as an economic determinant and NHIF contribution $(r=-1.177, \mathrm{p}=0.015)$.

The study therefore established that the multivariate analysis established a significant relationship between GDP and NHIF contribution and hence GDP in the 47 County Governments can be used to predict NHIF contribution in Kenya. The null hypothesis $\mathrm{HO}_{3}$ that the combined socioeconomic factors among the 47 counties in Kenya do not significantly influence NHIF contribution was rejected. This is because the study established that level of education, level of income and GDP had significant relationship with NHIF contribution in Kenya. It is important to note that when GDP was regressed individually, it did not influence NHIF contribution but when the three socioeconomic determinants were compressed in multivariate regression, GDP influenced the NHIF contribution. The finding is corroborated by the fact that different trends in international insurance markets affect the economic growth and fiscal policy of health expenditures in each region, provides these findings with a guide that governments can use during the evaluation and implementation of their health spending policies as well as the evaluation of their possibilities [31]. Finally, the intrarelationship effects of variables, a concern for future studies, are not considered in this paper. This imply that NHIF contributors seems encouraged more to contribute when they consider all the three socioeconomic determinants (Level of education, income level and GDP of their respective counties) on one hand, whereas on the other hand when the determinants are considered individual, the contributes found that the individual county's GDP had no influence on their contribution to NHIF.

Each of the data entities had information on the combined 
relationship between the socioeconomic determinants and the absorption of NHIF needed for all 7 years, indicating that the panels were strongly balanced. Of the form given by the following equation, the general form of the random effect model structure adopted was;

$$
\mathrm{Y}_{i t}=\beta 0+\beta 1 \mathrm{X} 1_{i t}+\begin{gathered}
\beta 2 \mathrm{X} 2_{i t}+\beta 3 \mathrm{X} 3_{i t}+\mathrm{uit} \text { random effect } \\
\text { equation }
\end{gathered}
$$

Where Xit is the determinants' predictor variable and Yit is the dependent variable, the NHIF contribution assumes the homogeneity of estimates across entities in the random effect model and the independent variable assumes that the likelihood of NHIF absorption varies over time but has a random effect across entities, $\beta_{1}$ is the coefficients of the regressor variables and $\mathrm{a}_{0}$ is the coefficient of the predictor variable and $\mu$ it is error term.

\begin{tabular}{|c|c|c|c|c|c|c|}
\hline \multirow[t]{2}{*}{ SS } & & $\mathrm{df}$ & MS & & Number of obs & 329 \\
\hline & & & & & $\mathrm{F}(3,325)$ & 5.57 \\
\hline Model & 1882.2 & 3 & 627.4 & & Prob $>F$ & 0.001 \\
\hline Residual & 36623.4 & 325 & 112.7 & & R-squared & 0.489 \\
\hline Total & 38505.6 & 328 & 117.4 & & Adj R-squared & 0.401 \\
\hline & & & & & Root MSE & 10.615 \\
\hline absob & Coef. & Std. Err. & $\mathrm{t}$ & $\mathrm{P}>\mathrm{t}$ & [95\% Conf. & Interval] \\
\hline education & 0.02766 & .0001071 & 2.58 & 0.010 & 0.0000658 & 0.0004873 \\
\hline gdp & -1.207783 & .4643081 & -2.60 & 0.010 & -2.121212 & -0.2943544 \\
\hline cons & 16.81245 & .8573246 & 19.61 & 0.000 & 15.12584 & 18.49905 \\
\hline
\end{tabular}

Table 10. Multivariate Random Effect of Socioeconomic Factors and NHIF Absorption.

The overall $\mathrm{R}^{2}$ was 0.489 indicating that $49 \%$ of the variance of NHIF absorption is explained by the socioeconomic determinants in the 47 County Governments compared to $51 \%$ which were explained by other factors outside the current study. The study established a statistically significant relationship between the socioeconomic determinants in the 47 County Governments and NHIF absorption as per table 10 . The $\mathrm{F}$ value for NHIF absorption was significant $(F 3,325)=5.57, p=0.001)$. This implies that there is a significant effect of education level in the 47 County Governments on NHIF contribution in Kenya. Education level in the 47 County Governments therefore could be used to predict the NHIF absorption in Kenya.

This finding indicated that an increase in the education level in the 47 County Governments by 1 unit will lead to increase in NHIF absorption by 0.02776 multiple units. This implies that education level in the 47 County Governments was a predictor of the NHIF absorption in Kenya. Secondly, income level in the 47 County Governments therefore could be used to predict the NHIF contribution in Kenya. This finding indicated that an increase in the income level in the 47 County Governments by 1 unit will lead to increase in NHIF absorption by 0.0224 multiple units. This implies that income level in the 47 County Governments was a predictor of the NHIF contribution in Kenya as demonstrated by the fact that the effect on the frequency of use of gender, income status and type of membership (probably representing socioeconomic characteristics). Lack of information on how to file claims and on the profit catalogue as important predictors of under-use [33]. Although at bivariate analysis the study established insignificant relationship between GDP and NHIF contribution, when the researcher carried out multivariate analysis, the study established a significant relationship between GDP as an economic determinant and NHIF contribution $(\mathrm{r}=-1.20778, \mathrm{p}=0.010)$. The study therefore established that the multivariate analysis established a significant relationship between GDP and NHIF absorption and hence GDP in the 47 County Governments can be used to predict NHIF absorption in Kenya.

The null hypothesis $\mathrm{HO}_{4}$ that the combined socioeconomic factors among the 47 counties in Kenya do not significantly influence NHIF absorption was rejected. This is because the study established significant relationship between level of education, level of income and GDP had significant relationship with NHIF absorption in Kenya. It is important to note that when GDP was regressed individually, it did not influence NHIF absorption but when the three socioeconomic determinants were compressed in multivariate regression, GDP influenced the NHIF absorption. This imply that NHIF contributors seems encouraged more to contribute when they consider all the three socioeconomic determinants (Level of education, income level and GDP of their respective counties) on one hand, whereas on the other hand when the determinants are considered individual, the contributes found that the individual county's GDP had no influence on their contribution to NHIF. Quality of care within hospitals is can change public perceptions on NHIF insurance and leading to improved uptake among low-income households [39, 40].

\section{Conclusions}

The main aim of this investigation was to analyze socioeconomic determinants of National Hospital Insurance Fund contributions and absorption: A Time Series Investigation among the Counties in Kenya. Findings on the relationship between socioeconomic determinants and NHIF contributions and absorption, established that at individual socioeconomic determinants level, education level and income level had a significant relationship with both NHIF contributions and absorption. Further findings on relationship between combined socioeconomic determinants and NHIF contributions and absorption established that all the determinants including counties GDP had significant relationship with NHIF contributions and absorption. 


\section{Limitations}

The investigation was based on panel data on socioeconomic determinants extracted from the Kenya Economic Review (2014-2020) and also panel data on NHIF contributions and absorption extracted from NHIF audited financial reports (2014-2020). Since the investigation related socioeconomic factors and NHIF contributions and absorption which requires triangulation from primary source which can be used to analyze perceptions and feelings which panel data could not achieve. Primary data might have corroborated the findings by making it clearer and expansive which the current study did not analyze. Secondly, the study analyzed three socioeconomic determinants; counties level of education, counties level of income and counties GDP which was the limitation.

\section{Implication for Policy, Practice and Future Research}

\subsection{Implication for Policy and Practice}

Although a policy review on NHIF contribution and absorption have been undertaken in the past, the study revealed that NHIF contribution and absorption gap was still wide. There is a policy need to further narrow the existing gap by reducing administrative costs of NHIF to practically narrow the established gap between NHIF contribution and absorption. The management of NHIF should carry out a survey among the beneficiaries to understand what affect them as far as their contribution is concern. The management should further engage the beneficiaries to assess their understanding on where their contributions should be used to meet their medical bills rather than the management deciding on their behalf.

\subsection{Implication for Future Research}

The current study investigated socioeconomic determinants of National Hospital Insurance Fund contributions and absorption: A Time Series investigation among the Counties in Kenya. The study analyzed three socioeconomic determinants; counties level of education, counties level of income and counties GDP which was the limitation. Further research should be carried out on other socioeconomic determinants to establish the extent they influence NHIF contributions and absorption in Kenya.

\section{References}

[1] Barasa, E., Nguhiu, P. \& McIntyre, D. (2018). Measuring progress towards sustainable development goal 3.8 on Universal Health Coverage in Kenya, BMJ Glob Heal, 1 (13). doi: 10.1136/bmjgh-2018-000904.

[2] Barasa, E., Rogo, K., Mwaura, N. \&Chuma, J. (2018). Kenya National Hospital Insurance Fund Reforms: Implications and Lessons for Universal Health Coverage, Health Systems \& Reform, 4: 4, 346-361, DOI: 10.1080/23288604.2018.1513267.
[3] Bendig, M. (2011). Enrolment in Micro Life and Health Insurance: Evidences from Sri Lanka.

[4] Bredenkamp, C., Buisman, L. R., Prencipe, L. M., Somanathan, A., Tsilaajar, T. and and Wagstaff, A. (2012). Mongolia - health equity and financial protection report, working paper, World Bank, Washington, DC.

[5] Deolitte, C. L. (2011). A Strategic Review of NHIF and Market Assessment of Private Prepaid Health Schemes, Nairobi: Ministry of Medical Services.

[6] Fang, K., Shia, B., \& Ma, S. (2012b). Health Insurance Coverage and Impact: A Survey in Three Cities in China, $\begin{array}{llll}P L O S & \text { ONE, (6), } & & \text { e39157. }\end{array}$ https://doi.org/10.1371/journal.pone.0039157.

[7] Faraon, E. J. A., Estrada, J. A. G., Farillas, E. L. F,, et al. (2013). Significant predictors of underutilization of inpatient benefits among philhealth members in selected Barangays in Manila, Acta Med Phil, 47, pp/69-73.

[8] Ghosh, M. (2013). Awareness and Willingness to Pay for Health Insurance: A Study Inof Darjeeling District, IOSR Journal Of Humanities And Social Science (IOSRJHSS), 12 (1), 41-47. Retrieved from www.Iosrjournals.Org.

[9] Health Financing Profile. (2016). Health financing profile, Kenya 2016. Retrieved from https://www.healthpolicyproject.com/pubs/7887/Kenya_HFP. pdf.

[10] IFC (2011). Strategic review of the National Hospital Insurance FundKenya. Nairobi (Kenya): Deloitte; 2011.

[11] Jowett, M. (2015). Raising revenues for health in support of UHC: strategic issues for policy makers, Geneva (Switzerland): WHO.

[12] Kenya National Bureau of Statistics. (2018). Kenya Integrated Household Budget Survey (KIHBS) 2015/16.

[13] Kimani, J. K, Remare, E., Kyobutungi, C., Mberu, B. and Muindi, K., (2012). Determinants for participation in a public health insurance program among residents of urban slums in Nairobi, Kenya: results from a cross sectional survey; $B M C$ Health Services Research (12) 66.

[14] Kimani, J. K., Ettarh, R., Warren, C., \& Bellows, B. (2014). Determinants of health insurance ownership among women in Kenya: evidence from the 2008-09 Kenya demographic and health survey, International Journal for Equity in Health, 13 (1), 27. https://doi.org/10.1186/1475-9276-13-27.

[15] KIPPRA. (2018). Kenya Institute for Public Policy Research and Analysis Policy Monitor, (9 No. 3). Retrieved from www.kippra.org.

[16] Kuan-Min, Wang \& Yuan-Ming, Lee (2018) The impacts of life insurance asymmetrically on health expenditure and economic growth: dynamic panel threshold approach, Economic Research-Ekonomska Istraživanja, 31 (1), pp. 440460, DOI: 10.1080/1331677X.2018.1429943.

[17] Lagomarsino, G., Garabrant, A., Adyas, A., Muga, R. \&Otoo, N. (2012). Moving towards universal health coverage: health insurance reforms in nine developing countries in Africa and Asia, Lancet, 380 (9845), pp. 933-943. doi: 10.1016/S01406736(12)61147-7. 
[18] McIntyre, D., Ranson, M. K., Aulakh, B. K. \& Honda, A. (2013). Promoting universal financial protection: evidence from seven low- and middle-income countries on factors facilitating or hindering progress, Health Res Policy Syst, 11 (1) pp. 36. doi: 10.1186/1478-4505-11-36.

[19] Maina, J. M., Kithuka, P., \& Tororei, S. (2016). Perceptions and uptake of health insurance for maternal care in rural Kenya: a cross sectional study. The Pan African Medical Journal, 23 125. https://doi.org/10.11604/pamj.2016.23.125.8936.

[20] Mbau, R., Kabia, E., Honda, A., Hanson, K. \&Barasa, E. (2018). Strategic purchasing in healthcare in Kenya: examining purchasing reforms by the National Hospital Insurance Fund. Nairobi (Kenya): RESYST.

[21] Mhere, F. (2013). Health insurance determinants in Zimbabwe: Case of Gweru Urban, Journal of Applied Business and Economics, 14 (October 2009), 62-79.

[22] MoH-Kenya. (2014). Kenya Health Sector Referral Strategy. Ministry of Health Division of Emergency and Disaster Risk Management Afya House.

[23] MoH (2017). Kenya national health accounts 2015/2016. Nairobi (Kenya): Ministry of Health.

[24] Mukhwana, E. S., Ngaira, J. K \& Mutai, C. (2015). Strategies to Enhance Utilization of National Hospital Insurance Fund Scheme Medical Cover by Informal Sector Populations in Kakamega County, Kenya, Universal Journal of Public Health, 3 (5), pp. 180-186.

[25] Munge, K., Mulupi, S., \& Chuma, J. (2015). A critical analysis of the purchasing arrangements in Kenya: the case of the National Hospital Insurance Fund, International Journal of Health Policy and Management, 7 (3), 244-254. Doi: 10.15171/ijhpm.2017.81.

[26] Muriithi, M. (2016). Strides towards universal health coverage for all Kenyans. Retrieved from https://kemriwellcome.org/wp-content/uploads/2020/12/200MEASURINGPROGRESS-TOWARDS-UNIVERSALHEALTHCARE-COVERAGE.pdf.

[27] Mwaura, R. N., Barasa, E., Ramana, G., Coarasa, J., Rogo, K., Klingen, N., \&Yazbeck, A. (2015). The Path to Universal Health Coverage in Kenya: Repositioning the Role of the National Hospital Insurance Fund. Smartlessons: Real Experiences, Real Development, (June), 1-4.

[28] National Hospital Insurance Fund. (2015). NHIF Annual report 2015. Nairobi: Author. retrieved from https://www.google.com/url?sa=t\&rct=j\&q=\&esrc=s\&source $=$ web $\& \mathrm{~cd}=13 \& \mathrm{cad}=\mathrm{rj}$ a\&uact $=8 \&$ ved $=2$ ahUKEwjlobqP1OfkAhWo3OAKHYJACd4 QFjAMegQIARAC\& url=http $\% 3 \mathrm{~A} \% 2 \mathrm{~F} \% 2 \mathrm{Fwww}$. oagkenya.go.ke $\% 2$ Findex.php $\% 2$
Freports\%2Fdoc download\%2F1549-national-hospitalinsurancefund\&usg=AOvVaw1U3LBU15hk4VK4v-g7sVTy.

[29] National Hospital Insurance Fund.(2018). Strides towards universal health coverage for all Kenyans. Retrieved from http://www.nhif.or.ke/healthinsurance/uploads/notices/NHIF Performance_Report_2018_08.08.2018.pdf.

[30] Nguyen, K. T., Khuat, O. T. H., Ma, S., Pham, D. C., Khuat, G. T. H., \&Ruger, J. P. (2012). Impact of health insurance on health care treatment and cost in Vietnam: a health capability approach to financial protection, American Journal of Public Health, 102 (8), https://doi.org/10.2105/AJPH.2011.300618.

[31] Ombiro, O. N. (2019). Utilization of National Hospital Insurance Fund among community members in Embu County, Kenya, Unpublished Thesis, Kenyatta, Kenya.

[32] Ongiri, I., \& Kubani, J. (2015). Unions demand talks on NHIF rates. Daily Nation, p. 17.

[33] Owusu-Sekyere, E., \& Chiaraah, A. (2014). Demand for Health Insurance in Ghana: What Factors Influence Enrollment? American Journal of Public Health Research, 2 (1), 27-35. https://doi.org/10.12691/ajphr-2-1-6.

[34] Oxfam (2013). Universal Health Coverage - Why Health Insurance Schemes Are Leaving the Poor Behind. Oxford: Oxfam.

[35] Oyekale, A. S. (2012). Factors Influencing Households , Willingness to Pay for National Health Insurance Scheme (NHIS) in Osun State, Nigeria, 6 (3), 167-172.

[36] Sachs, J. D. (2012). Achieving universal health coverage in low-income settings, Lancet, 380 (9845), pp. 944-947. doi: 10.1016/S0140-6736(12)61149-0.

[37] Tadashi, Y., Tetsuji, Y., Chia-Ching, Chen \&Weihong, Z. (2014). Determinants of health insurance and hospitalization, Cogent Economics \& Finance, 2 (1), DOI: 10.1080/23322039.2014.920271.

[38] Thuita, G. R. (2017). Determinants of Health Insurance Uptake Among Women in Kenya: An Application of Discriminant Analysis School of Mathematics, (26).

[39] Veloshnee, G. Matthew, F. Chersich, B. H., Olufunke, A., John, E. Ataguba, Nonhlanhla, N. \& Goudge, J. (2013). Moving towards universal coverage in South Africa? Lessons from a voluntary government insurance scheme, Global Health Action, 6 (1), DOI: 10.3402/gha.v6i0.19253.

[40] Wang, Y., Jiang, Y., Li, Y., Wang, X., Ma, C., \& Ma, S. (2013). Health insurance utilization and its impact: Observations from the middle-aged and elderly in China, $\begin{array}{lllll}P L O S & O N E, & 8 & \text { (12), } & \text { e80978. }\end{array}$ https://doi.org/10.1371/journal.pone.008097. 